\title{
Understanding local variation in how female genital mutilation/ cutting declines, changes, or persists: Analysis of household survey data for Kenya, Nigeria, and Senegal
}

Population Reference Bureau

Follow this and additional works at: https://knowledgecommons.popcouncil.org/departments_sbsr-rh

Part of the Demography, Population, and Ecology Commons, Family, Life Course, and Society Commons, Gender and Sexuality Commons, International Public Health Commons, and the Medicine and Health Commons How does access to this work benefit you? Let us know!

\section{Recommended Citation}

Population Reference Bureau. 2020. "Understanding local variation in how female genital mutilation/ cutting declines, changes, or persists: Analysis of household survey data for Kenya, Nigeria, and Senegal," Evidence Brief, February. Washington, DC: Population Reference Bureau (PRB). 


\title{
Understanding Local Variation in How Female Genital Mutilation/Cutting Declines, Changes, or Persists
}

\author{
Analysis of Household Survey Data for Kenya, Nigeria, and Senegal
}

\author{
The Evidence to End FGM/C \\ programme consortium \\ generates evidence to \\ inform and influence \\ investments, policies, and \\ programmes for ending \\ female genital mutilation/ \\ cutting in different contexts.

\section{Population Council} \\ Lead Institution
}

Africa Coordinating Centre for the Abandonment of Female Genital Mutilation/Cutting, Kenya (ACCAF)

Global Research and Advocacy Group, Senegal (GRAG)

MannionDaniels Ltd. (MD)

Population Reference Bureau (PRB)

University of Washington (Prof. Bettina Shell-Duncan)

University of California, San Diego (Dr. Gerry Mackie)

\section{Funded by}

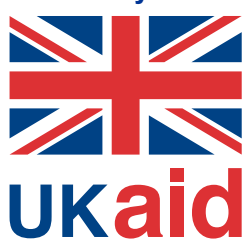

from the British people
Using advanced statistical modelling in Kenya, Nigeria, and Senegal,

Evidence to End FGM/C consortium researchers show that:

- Prevalence of female genital mutilation/cutting (FGM/C) tends to be concentrated in certain subregions and locations.

- Local social norms are a key factor driving the practice in all three countries.

These findings underscore the importance of subnational policies in initiatives to end FGM/C and provide evidence for investing in community-level interventions that promote shifts in social norms, including religious norms.

Efforts to eliminate female genital mutilation/cutting (FGM/C) intensified in many parts of Africa following a 2012 United Nations General Assembly Resolution, but change has been uneven-dramatic in some places and limited in others. Important evidence gaps remain in our understanding of why the practice declines, changes, or persists in specific locations. Policy makers and programme planners need such information to better tailor interventions to address local patterns and focus resources on abandonment efforts in areas with the greatest needs.

To fill these information gaps, researchers with the Evidence to End FGM/C consortium used advanced statistical methods (multivariate spatial analysis) to analyse nationally representative household survey data for Kenya, Nigeria, and Senegal. This approach allowed them to examine $\mathrm{FGM} / \mathrm{C}$ prevalence as it varied over time and by geographic location. They focused the analyses on data for the youngest group (younger than 15 years) because patterns of $\mathrm{FGM} / \mathrm{C}$ prevalence among this age group reflect the most recent changes to the practice. The results of their research-detailed in a set of separate working papers-identify geographic "hot spots" with high FGM/C prevalence, explore changes to the practice, and analyse individual and community characteristics linked to a greater likelihood of FGM/C (see Appendix, page 9).

These findings provide a deeper understanding of local trends and identify some of the specific factors responsible for driving change in each of the three countries. This evidence brief summarises the key findings for all three countries and their implications for policy making and programme planning.

\section{Uncovering Geographic Hot Spots}

Analysis of household data for all three countries shows that the practice varies significantly by geographic area within countries. Research suggests FGM/C is sustained across generations in part by expectations and norms within a social or religious group at the community level. People living in proximity are more likely to influence each other's expectations of appropriate behaviour. Forgoing FGM/C in isolation is difficult for an individual family living in a community that supports the practice: Girls may be less marriageable, and families may be ostracised. ${ }^{1}$ 
Pinpointing local areas with high FGM/C prevalence (hot spots) can help programme planners focus resources on abandonment efforts in these communities. To identify hot spots, researchers estimated prevalence using advanced statistical methods that linked data on individual FGM/C status to specific geographic areas, adjusting for individual and community factors (also known as adjusted or predicted prevalence). This multistep approach (multilevel modelling) enabled them to capture FGM/C patterns potentially related to community norms in subnational areas.

\section{KENYA}

The researchers analysed nationally representative survey data on FGM/C from four waves of Kenya Demographic and Health Surveys (KDHS), conducted in 1998, 2003, 2008-09, and 2014. They used a technique known as survival analysis to predict the likelihood that a girl younger than 15 years would be cut based on regional patterns and her personal characteristics. The researchers estimated and mapped FGM/C prevalence at the national and county level. As part of this analysis, they adjusted for individual and community factors; examined patterns of change over time; incorporated the results of the survival analysis; and accounted for differences in survey questions and coverage in successive years.

The results show that overall, national FGM/C prevalence among girls younger than 15 years declined during the 16-year period (see Figure 1). In 1998, prevalence in many counties was above 25 percent. By 2014, prevalence in most counties was below 20 percent. The lowest 2014 prevalence was in the central counties, which include Nairobi, the capital. The analysis identified five hot spot counties with prevalence levels above 20 percent in 2014:

- Three northeast counties-Mandera, Wajir, and Garissa—which represent a geographically isolated region bordering Somalia and Ethiopia whose residents are primarily ethnic Somalis. The 2014 FGM/C prevalence in these three northeast Kenya hot spot counties was 47 percent, 46 percent, and 36 respectively, reflecting no change over the 16-year period. (As a group, Somalis living in Somalia have the world's highest level of FGM/C: 97 percent for girls 15 to 19 years). ${ }^{2}$

- The southwest counties of Kisii and Nyamira, which are areas characterised by limited ethnic diversity, where most residents are ethnic Kisii. The 2014 prevalence in these southwest counties was 24.4 percent and 22.5 percent, respectively, reflecting a slight decline in the 16 -year period.

FIGURE 1

\section{FGM/C Declined in Most Counties, But Remained High in Hot Spot Counties in Kenya's Northeast and Southwest}

Predicted FGM/C Prevalence Among Kenyan Girls, 0-14 Years, Adjusting for Individual and Community Factors, by County, 1998 to 2014



Source: Kandala, Ngianga-Bakwin et al. 2017. "Modelling and mapping of girls' female genital mutilation/cutting (FGM/C) in the context of economic, social, and regional disparities: Kenya Demographic and Health Surveys 1998-2014." Evidence to End FGM/C: Research to Women Thrive. New York: Population Council. 
Researchers found wide variation in FGM/C prevalence across the country among geopolitical zones and states. They used six nationally representative datasets from the Nigeria Demographic and Health Surveys (NDHS) (2003, 2008, and 2013) and Multiple Indicator Cluster Surveys (MICS) $(2007,2011$, and 2016-17) to estimate prevalence among girls younger than 15 years. Their multivariate analysis examines FGM/C prevalence by location and over time as well as their interactions, while adjusting for a variety of individual factors. A girl's likelihood of being cut increased if her mother was cut or supported FGM/C continuation or both, suggesting community-level social norms play a role in the practice.

Overall, findings show that FGM/C prevalence among girls younger than 15 years declined during the period in the South but increased in the North since 2008. The national prevalence increased from 17.3 percent in 2003 to 30 percent in 2008, with most states above 30 percent in the South West and South East zones. By 2016-17, the national prevalence had dropped to 25.3 percent, with most states below 20 percent. The lowest 2016-17 prevalence was in the North East zone.

The researchers report that these trends are not explained by the survey data, but they may reflect better data collection in successive surveys, internal migration, differences in implementation of national legislation banning FGM/C at the state level throughout the country, and the impact of abandonment initiatives that had been focused mainly in the South.

In Nigeria, a girl's likelihood of being cut increased if her mother was cut or supported FGM/C continuation or both, suggesting community-level social norms play a role in the practice.

Figure 2 shows the estimated FGM/C prevalence based on multivariate analysis of state-level data for the two most recent surveys (NHDS 2013 and MICS 2016-17). After adjusting for individual factors and the interactions of both location and time, hot spots with high FGM/C prevalence among girls younger than 15 years in 2016-2017 included Jigawa, Kano, Kaduna, and Zamfara states in the North West zone and Ekiti state in the South West zone, with prevalence ranging from 74 percent in Kano and Zamfara to 42 percent in Ekiti (shown in Figure 2 in red or bright red). Between 2013 and 2016-17, other southern states saw declines, while Zamfara state (western most state appearing in red in the north) saw a dramatic increase.

\section{FIGURE 2}

\section{FGM/C Hot Spots Are Concentrated in States in Nigeria's North West and South West Zones}

Estimated FGM/C Prevalence, Among Nigerian Girls, 0-14 Years, Adjusting for Individual and Community Factors, by State, 2013 and 2016-17
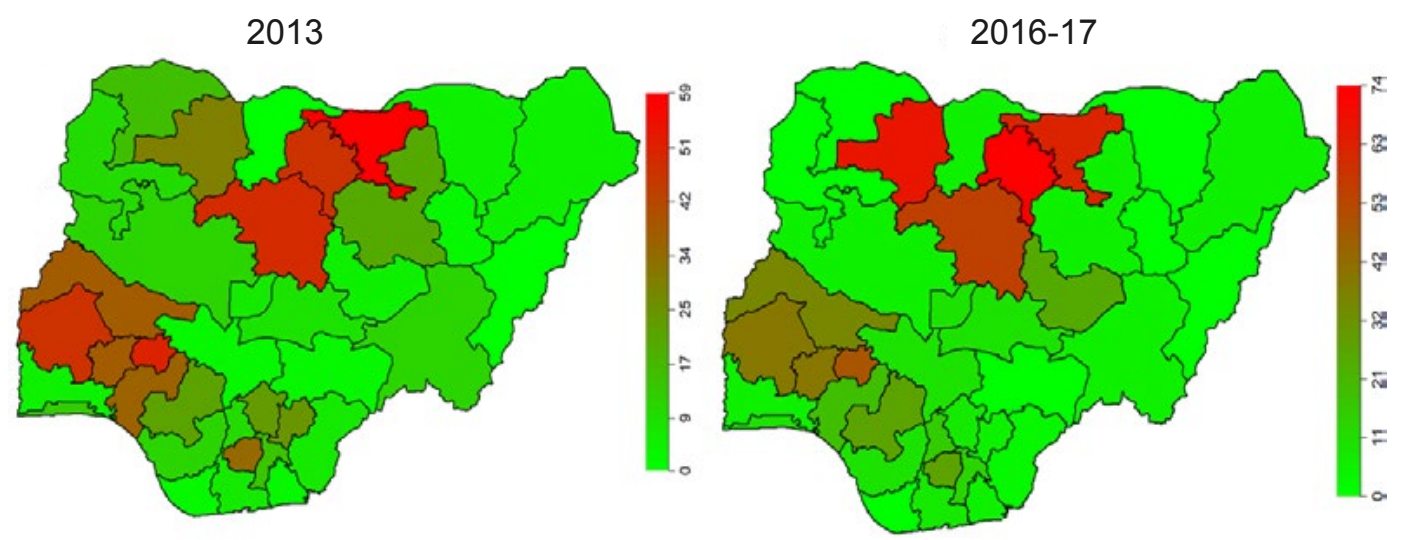

Note: Each map shows estimated FGM/C prevalence by state compared to the state with the lowest level. Because the ranges vary between the results of the two surveys, the scales are slightly different.

Source: Unpublished analysis by the Evidence to End FGM/C research consortium. 


\section{SENEGAL}

The researchers analysed data from the Senegal Demographic and Health Surveys (SDHS) covering 2005, 2010-11, 2015, and 2017. Results show that at the national level FGM/C prevalence for girls declined between 2005 and 2010-11, but stagnated between 2010-11 and 2017. Specifically, the national prevalence decreased from 20.4 percent in 2005 to 11.4 percent in 2010-11, then increased to 15 percent in 2015 and remained at the same level in 2017. In 2015 the national prevalence was 15 percent with most regions below 50 percent. By 2017, the national prevalence had stagnated at 14 percent, with most regions below 20 percent.

Multivariate analysis examined the regional variation in $\mathrm{FGM} / \mathrm{C}$ prevalence, incorporating the survival analysis results that predicted the likelihood uncut girls would be cut before age 15 years. Their findings show a girl's likelihood of being cut increased with the proportion of cut women in her community, suggesting local social norms play a key role in sustaining FGM/C.

Analysis of the fully adjusted data for 2010-11, 2015, and 2017 shows hot spots with the highest estimated FGM/C prevalence in the Matam, Tambacounda, and Kolda regions in 2017 (shown in Figure 3 in bright or medium red; 58.5 percent, 46.9 percent, 35.2 percent, respectively). Regions along the southern border experienced both increases and declines in FGM/C prevalence, potentially reflecting cross-border migration from high prevalence neighbouring countries such as Mali, Guinea, and Guinea-Bissau. Prevalence in regions in the west remained consistently low during the period.

In Senegal, a girl's likelihood of being cut increased with the proportion of cut women in her community, suggesting local social norms play a key role in sustaining FGM/C.

\section{FIGURE 3}

\section{FGM/C Hot Spots Are Mainly Concentrated Along Senegal's Eastern and Southern Borders}

Estimated FGM/C Prevalence Among Senegalese Girls, 0-14 Years, Adjusting for Individual and Community Factors, by Region, 2010-11, 2015, and 2017
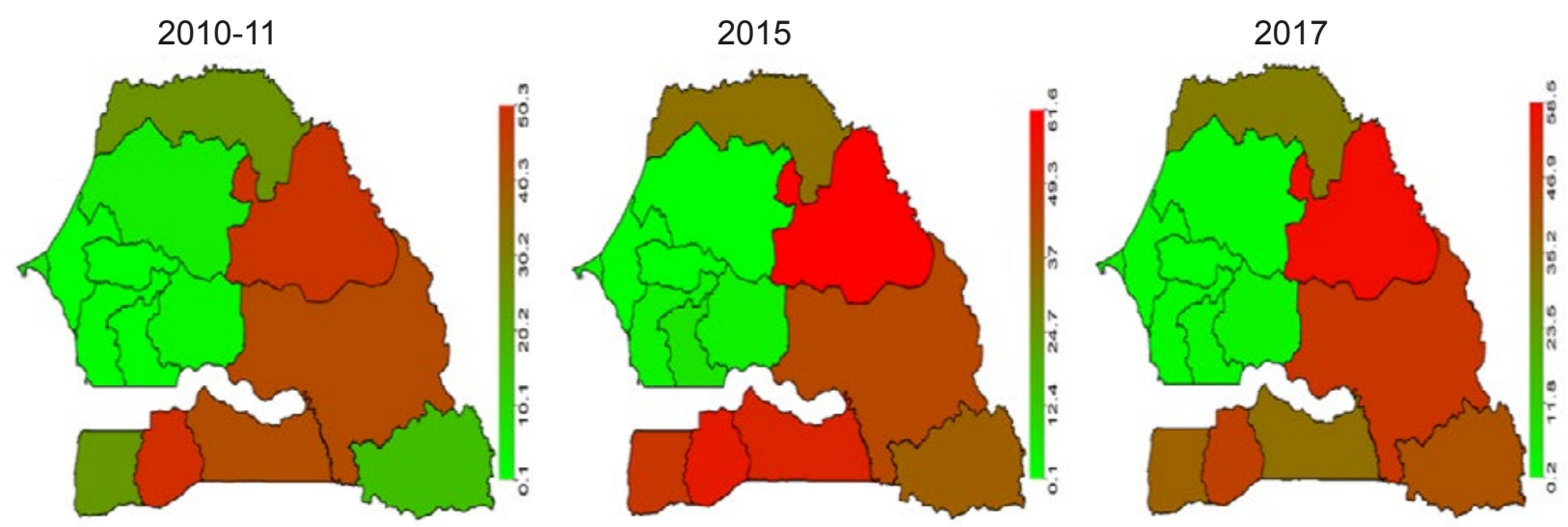

Note: Each map shows FGM/C prevalence estimates by region compared to the region with the lowest level. Because the ranges vary among the results of the three surveys, the scales are slightly different.

Source: Kandala, Ngianga-Bakwin et al. 2020. "Modelling and mapping of female genital mutilation/cutting and risk factors among girls 0-14 years in Senegal: Evidence from Senegal Demographic and Health Surveys, 2005-2017." Evidence to End FGM/C: Research to Help Girls and Women Thrive. New York: Population Council (forthcoming). 


\section{Identifying Patterns in Age at Cutting to Shape Abandonment Efforts}

Identifying the age at which girls tend to be cut can inform the design of abandonment efforts, better tailoring them to the local context. For example, if most girls are cut as infants, abandonment initiatives that seek to reshape coming-of-age rituals for preteen girls do not address local practice.

\section{KENYA}

The survival analysis technique using 2008 DHS data enabled the researchers to identify patterns in the predicted age at cutting. The results document that FGM/C occurred at much younger ages among girls in the 2008 survey compared with their mothers' generation. Girls undergo the most severe forms much earlier than other types: 'Sewn closed' or 'stitched up' FGM/C (Type III) occurs earliest, just after birth, followed by less severe FGM/C (Types I and II) (see box). Researchers linked several individual characteristics to the age at which girls experience the practice:

- Residence (rural-urban): Girls faced similar risks of being cut in rural and urban areas in the years before their 5th birthday. After age 5, FGM/C occurred earlier in urban areas. In rural areas, FGM/C continued until age 20 ; the practice stopped at 15 years in urban areas. Half of cut girls were cut by age 7 in rural areas and by age 8 in urban areas.

- Region: FGM/C occurred at younger ages in the Northeast (most cut girls were cut between ages 6 and 7) than in the Rift Valley and Central provinces (most cut girls were cut between ages 12 and 16, and between ages 14 and 16, respectively).

- Ethnicity and religion: FGM/C occurred earlier for Muslim girls (75 percent cut by age 8 ) and among ethnic Somali girls (75 percent cut by age 7 ).

- Mother's education and household socioeconomics: Daughters of mothers with low levels of education and girls in the poorest households tended to be cut at younger ages.

\section{NIGERIA}

Analysis of nationally representative data from the 2013 DHS suggests 50 percent of all the cut girls were cut by age 2. Evidence showed important shifts, with daughters being cut at a much earlier age than their mothers' generation and girls increasingly being subjected to less severe forms of FGM/C (for example, not sewn-closed). Several characteristics increased the likelihood a girl underwent the procedure earlier:

- Residence (rural-urban): Until age 1, the likelihood of undergoing FGM/C was similar in rural and urban areas. After age 1, FGM/C occurred earlier in urban than rural areas. FGM/C seemed to continue at the same rate in rural and urban areas in older age groups (10 to 14 years). Half of all cut girls in both rural and urban areas were cut by age 2, with 75 percent cut by age 3 in rural areas and by age 5 in urban areas.

- Region: The pattern of cutting differed markedly by region of residence with the practice occurring earliest in the North Central region with 75 percent of cut girls cut by age 3, followed by the South West with 75 percent cut by age 4 . In both regions, cutting rarely occurred after age 10.

- Ethnicity and religion: FGM/C occurred earlier among Yoruba girls (75 percent of cut girls cut by age 3 ) than among girls of other ethnicities such as Hausa (75 percent cut by age 10). Among minority ethnic groups such as Kanuri and Tiv with low prevalence of FGM/C, cutting occurred before age 3. Among girls under age 5, FGM/C occurred much earlier among Muslims than among other girls. The rate was indistinguishable after age 5 for all religious groups considered. 
Mother's education, attitudes, and FGM/C status: Mothers with higher levels of education had their daughters cut earlier (75 percent cut by age 3 ) than those with lower levels of education (75 percent cut by ages 4 or 5). Daughters of women who supported the practice of $\mathrm{FGM} / \mathrm{C}$ were cut earlier than those whose mothers were either ambivalent or opposed to FGM/C continuing. Daughters of cut women experienced FGM/C earlier than daughters of uncut women.

\author{
In Nigeria and \\ Senegal, 50 percent \\ of all the cut girls \\ were cut by 2 years.
}

\section{SENEGAL}

Survival analysis of 2017 SDHS data shows that 25 percent, 50 percent, and 75 percent of all cut girls underwent the procedure by 1,2 , and 3 years respectively. Further analysis indicated the following patterns among girls who were cut:

- Residence (rural-urban): In both rural and urban areas, half the cut girls were cut by age 2. Before age 2, the rate of cutting was similar, but cutting occurred earlier in rural areas between ages 3 and 8 . After age 8, FGM/C occurred at a similar rate in both areas.

- Region: Girls in southern regions were cut earliest (half cut by ages 1 or 2), while those in western regions were cut somewhat later (half cut by ages 3 or 4). The likelihood of being cut diminished across all regions after age 10.

- Ethnicity and religion: Soninke girls were cut earliest (half cut by age 1), while girls from most other ethnic groups underwent FGM/C slightly later (half cut by age 2) for all except Diola girls (half cut by age 3). Among Christian and Muslim girls, half of the cut girls were cut by age 2 .

- Mother's education: Daughters of women with primary, secondary, or no education were cut at the same rate; half of all cut girls were cut by age 2 .

\section{Understanding the Role of Individual Characteristics in FGM/C Trends}

Research shows the practice of FGM/C is linked to community and individual characteristics, such as membership in a specific religious or ethnic group, mother's education level, and share of cut women in the community. Some of these patterns are reinforced by community norms and expectations. Understanding these connections can help planners better design abandonment initiatives and focus them in areas with high prevalence.

\section{KENYA}

After adjusting for all other factors including location, analysis of data across 1998 to 2014 shows the likelihood of experiencing FGM/C remains high and statistically significant for girls with the following specific characteristics:

- Religion: Daughters of women who were Christian but not Roman Catholic were much less likely to experience FGM/C than daughters whose mothers were Muslim, Roman Catholic, or practise no religion.

- Household socioeconomics and mother's education: Daughters of mothers with no education and living in poor rural households were more likely to undergo FGM/C. Analysis of data over the 16-year period shows that as women's education level increases, daughters were less likely to undergo $\mathrm{FGM} / \mathrm{C}$.

- Mother's FGM/C status and attitudes: Daughters were more likely to undergo FGM/C in communities where more women are cut, a greater number of women support the continuation of $\mathrm{FGM} / \mathrm{C}$, and more women believe that the practice is required by the community and/or by religion, reflecting the role of social norms and expectations in the continuation of the practice. 
In addition, Kisii and Somali ethnicity are strongly linked to a greater likelihood of FGM/C in analysis that does not adjust for location. But in fully adjusted analysis that accounts for location, ethnicity is no longer significantly linked to the likelihood of undergoing FGM/C, suggesting that local norms and expectations in Kisii and Somali communities are the driving factor in decisions to have daughters cut rather than ethnicity.

\section{NIGERIA}

Analysis of six sets of survey data collected between 2003 and 2016-17 suggests the following patterns:

- Residence (rural-urban): Girls who lived in rural areas had a higher likelihood of undergoing $\mathrm{FGM} / \mathrm{C}$ than their urban counterparts across most survey years.

- Religion: Daughters of Muslim women were more likely to be cut than their counterparts whose mothers were Christian.

- Region: Girls who lived in the North West or South West geopolitical zones had higher likelihood of experiencing FGM/C than girls who lived elsewhere in the country.

- Household socioeconomics, and mother's education and autonomy: After adjusting for other factors, FGM/C prevalence was higher in poorer households in Nigeria. A girl was more likely to be cut if her mother had a low level of education; an informal or no job; lacked sole decision-making power on how she spent her own cash and on making large household purchases; and did not read newspapers or magazines, or watch television.

- Mother's attitudes and beliefs: Daughters of women who were cut, supported FGM/C continuing, or believed that FGM/C would enhance a girl's marriageability were more likely to be cut than their counterparts.

\section{SENEGAL}

The multivariate analysis of the pooled 2010 to 2017 SDHS data suggests that social norms and ethnicity are key factors driving FGM/C among Senegalese girls. During the period, the researchers noted that FGM/C appeared to decline among residents of multiethnic communities that include groups that do and do not practise FGM/C. They hypothesise that social connections among people living and working in the same location may contribute to practising groups re-evaluating prior norms. They identified the following patterns:

- Residence (rural-urban): Girls living in rural areas were 50 percent more likely to be cut than their urban peers.

- Religion: Christian girls were less likely to be cut than their peers belonging to other religious groups.

- Mother's status, attitudes, and beliefs: A girl's probability of being cut was higher if her mother was cut, supported the continuation of $\mathrm{FGM} / \mathrm{C}$, or believed that the practice was a religious obligation, suggesting that social norms play a key role. A girl's likelihood of experiencing FGM/C increased when the proportion of cut women in her community exceeded 30 percent, further underscoring the role of community norms.

- Ethnicity: Mother's ethnicity strongly influenced whether a girl would experience FGM/C. Being born to a mother from Diola, Mandigue, Soninke, or Poular ethnic groups increased a girl's likelihood of being cut. Wolof and Serer girls were least likely to be cut.

\section{In Nigeria, FGM/C prevalence was higher among girls living in poorer households and in rural areas.}

\author{
In Senegal, a \\ girl's likelihood \\ of experiencing \\ FGM/C was strongly \\ influenced by her \\ mother's ethnicity.
}




\section{Policy and Programme Implications}

This analysis in Kenya, Nigeria, and Senegal by Evidence to End FGM/C consortium researchers shows that the prevalence of FGM/C tends to be concentrated in certain subregions and locations. Considering only national-level data may mask important local variations of the practice. By linking survey data to geographic locations, their analysis identifies high-prevalence hot spots that can benefit from investment in abandonment programmes. These findings underscore the importance of subnational policies and initiatives to end FGM/C.

Using advanced statistical modelling, the studies provide evidence that social norms are a key factor driving the practice in all three countries. The researchers identify ways in which FGM/C is linked to individual and community characteristics in specific areas, such as belonging to a certain ethnic or religious group and the share of cut women within the community. The researchers point out that individuals' decisions are shaped by common practices among the people where they live, and FGM/C persists because of shared expectations within social and religious groups. Understanding these dynamics can help planners design abandonment initiatives tailored to the local context that

Individuals' decisions are shaped by common practices among the people where they live, and FGM/C persists because of shared expectations within social and religious groups. contribute to shifts in community norms.

Specifically, these findings provide support for community-level interventions that promote shifts in social norms, including religious norms. Proven approaches involve partnerships among local governments, policymakers, and community and religious leaders. These interventions might prioritise:

- Hot spot communities where FGM/C prevalence is geographically concentrated.

- Religious groups where FGM/C prevalence is strongly linked to religious group membership and is incorrectly viewed as a requirement of the faith.

- Mothers who believe FGM/C enhances a girl's marriageability.

- Multiethnic communities that are home to ethnic groups that do and do not practise FGM/C.

Initiatives that promote gender equality and women's empowerment are especially warranted in social contexts where $\mathrm{FGM} / \mathrm{C}$ is higher among:

- Girls of mothers with informal or no employment.

- Daughters of women who lack economic decision-making power in their households.

Intervention plans should consider the age at which cutting tends to occur. For example, if cutting occurs in infancy and early childhood, behaviour-change interventions focused on the decision-making dynamics at the family and household level better address the local context than promoting alternative coming-of-age rituals.

Based on this set of findings, the researchers suggest that increasing educational attainment among girls and women, greater awareness of anti-FGM/C media messages, and growth in formal jobs for women may contribute to a climate that empowers women, reducing demand for FGM/C in the future.

\section{References}

1 Mackie, Gerry and John LeJeune. 2009. "Social dynamics of abandonment of harmful practices: A new look at the theory," Special Series on Social Norms and Harmful Practices. New York: UNICEF.

2 Madsen, Elizabeth Leahy and Kristin Bietsch. 2017. "Female genital mutilation/cutting: Data and trends update 2017." Washington, DC: Population Reference Bureau. https://www.prb.org/wp-content/uploads/2017/02/FGMC_Poster_2017-1.pdf. 


\section{Appendix}

This Evidence Brief summarises the key findings from the following working papers and journal article, as well as additional analyses.

\section{KENYA}

Shell-Duncan, Bettina, David Gathara, and Zhuzhi Moore. 2017. "Female genital mutilation/cutting in Kenya: Is change taking place? Descriptive statistics from four waves of Demographic and Health Surveys," Evidence to End FGM/C: Research to Help Women Thrive. New York: Population Council.

Kandala, Ngianga-Bakwin et al. 2017. "Modelling and mapping of girls' female genital mutilation/cutting in the context of economic, social, and regional disparities: Kenya Demographic and Health Surveys 1998-2014," Evidence to End FGM/C: Research to Help Women Thrive. New York: Population Council.

Kandala, Ngianga-Bakwin et al. 2019. "A spatial analysis of the prevalence of female genital mutilation/ cutting among 0-14-year-old girls in Kenya," International Journal of Environmental Research and Public Health 21 (16): doi.org/10.3390/ijerph16214155.

\section{NIGERIA}

Kandala, Ngianga-Bakwin et al. 2020. "Female genital mutilation/cutting in Nigeria: Is the practice declining? A descriptive analysis of successive Demographic and Health Surveys and Multiple Indicator Cluster Surveys (2003-2017)," Evidence to End FGM/C: Research to Help Girls and Women Thrive. New York: Population Council (forthcoming).

Kandala, Ngianga-Bakwin et al. 2020. "Modelling and mapping of state disparities associated with female genital mutilation/cutting prevalence among girls aged 0-14 years in Nigeria: Evidence from DHS and MICS 2003-2017," Evidence to End FGM/C: Research to Help Girls and Women Thrive. New York: Population Council (forthcoming).

\section{SENEGAL}

Matanda, Dennis et al. 2020. "Female genital mutilation/cutting in Senegal: Is the practice declining? Descriptive analysis of Demographic and Health Surveys, 2005-2017," Evidence to End FGM/C: Research to Help Girls and Women Thrive. New York: Population Council (forthcoming).

Kandala, Ngianga-Bakwin et al. 2020. "Modelling and mapping of female genital mutilation/cutting prevalence among girls 0-14 years in Senegal: Evidence from Senegal Demographic and Health Surveys, 2005-2017," Evidence to End FGM/C: Research to Help Girls and Women Thrive. New York: Population Council (forthcoming).

\section{Acknowledgments}

This Evidence Brief was produced by Population Reference Bureau for the Evidence to End FGM/C: Research to Help Girls and Women Thrive consortium, led by the Population Council and funded by UKAID. It was prepared by Paola Scommegna with technical guidance from Reshma Naik; Heidi Worley provided editorial input. Ngianga-Bakwin Kandala and Bettina Shell-Duncan provided the technical review; Charlotte Feldman-Jacobs and Caroline Kabiru offered insightful comments. Please address any inquiries about the Evidence to End FGM/C research consortium to: Dr. Jacinta Muteshi, Project Director, jmuteshi@popcouncil.org

Suggested citation: Population Reference Bureau. 2020. "Understanding local variation in how female genital mutilation/cutting declines, changes, or persists: Analysis of household survey data for Kenya, Nigeria, and Senegal." Evidence to End FGM/C Research Consortium Evidence Brief.

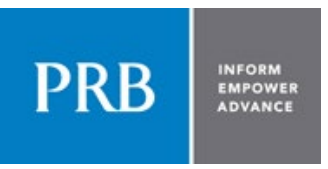

